\title{
Evaluation and correction of optically derived leaf area index in different temperate forests
}

Zhili Liu, Guangze Jin, Ming Zhou

\section{Introduction}

The leaf area index (LAI), which is defined as half the total green leaf area per unit ground surface area (Chen \& Black 1992), is an important canopy parameter required for many physiological and ecosystem studies (Macfarlane et al. 2007, Bequet et al. 2012, Beckschäfer et al. 2013). For instance, an accurate LAl estimation is essential for modeling light and precipitation interception, $\mathrm{CO}_{2}$ fluxes, evapotranspiration, and dry deposition (Jonckheere et al. 2005, Beckschäfer et al. 2014, Gonsamo \& Chen 2014, Zhao et al. 2014). In addition, LAI is

Center for Ecological Research, Northeast Forestry University, Harbin 150040 (China)

@ Guangze Jin (taxus@126.com)

Received: May 13, 2014 - Accepted: Mar 03, 2015

Citation: Liu Z, Jin G, Zhou M (2015). Evaluation and correction of optically derived leaf area index in different temperate forests. iForest 9: 55-62. - doi: 10.3832/ifor1350-008 [online 2015-06-11]

Communicated by: Giorgio Matteucci lection, Correlation
In recent years optical techniques for rapid LAI measurements have been developed, but few studies have been performed to evaluate the accuracy of optical estimation of LAl in mixed deciduous-evergreen forest stands. In this paper, we assessed the accuracy of digital hemispherical photography (DHP) and the LAl-2000 for the estimation of effective LAI $\left(L_{e}\right)$ by comparison with litter collection LAI $\left(L A l_{\text {itt }}\right)$ in four mixed deciduous broadleaf and evergreen needleleaf forests and one deciduous needleleaf forest. We also evaluated the relative contribution of major error sources to the determination of LAl by optical methods, including the woody-to-total area ratio (a), the element clumping index $\left(\Omega_{\mathrm{E}}\right)$ and the needle-to-shoot area ratio $\left(\gamma_{\mathrm{E}}\right)$. Additionally, incorrect automatic photographic exposure has been considered for DHP. DHP $L_{e}$ underestimated $L A l_{\text {lit }}$ by an average of $44-70 \%$ in different forests, and the difference between $L A I_{\text {lit }}$ and DHP $L_{\mathrm{e}}$ after correction for the automatic exposure, a, $\Omega_{\mathrm{E}}$ and $\gamma_{\mathrm{E}}$ ranged from $1 \%$ to $21 \%$ in five forest stands. In contrast, LAl values from LAI-2000 were more similar to the direct litter collection LAl. The LAl$2000 L_{\mathrm{e}}$ underestimated $L A I_{\text {lit }}$ by an average of $13-40 \%$ in these forests, while the accuracy of the best estimates of LAI using LAl-2000 methods is over $93 \%$ after considering $\mathrm{a}, \Omega_{\mathrm{E}}$ and $\gamma_{\mathrm{E}}$. The error caused by automatic exposure to DHP $L_{e}$ is larger than other factors in all forest stands, and the $\gamma_{E}$ was the main uncertainty to LAl-2000 $L_{\mathrm{e}}$ in most forest stands. Moreover, optical LAl (both DHP and LAl-2000) was significantly $(P<0.01)$ correlated with $L A l_{\text {lit }}$, especially the corrected LAl obtained by the LAl-2000 $\left(R^{2}=0.83\right.$, RMSE $\left.=1.04\right)$. Our results demonstrate that the above factors affect the estimation of LAl by optical methods, thus the species composition of a forest stand should be seriously considered in order to improve the accuracy of LAl by optical methods.

Keywords: Leaf Area Index (LAl), Digital Hemispherical Photography (DHP), LAl-2000, Woody Materials, Clumping Effects, Automatic Exposure, Litter Col- commonly used to compare canopy development or structure over time or under different environmental conditions or disturbances (Martens et al. 1993). Therefore, accurately estimating the LAI is of great interest, especially in tall forest systems.

Recently, direct and indirect methods have been recommended to estimate the LAI in a forest stand. Destructive sampling, allometry, and litter collection are the most commonly used direct methods (Chen et al. 1997, Bréda 2003, Jonckheere et al. 2004). Although the LAl value obtained is similar to the true values, such direct me- thods are time consuming and labor intensive, and especially destructive for the former two methods. In contrast, the litter collection method is the best choice for obtaining an accurate LAl in a forest stand, especially in protected areas. This method has traditionally been used to estimate the $\mathrm{LAI}$ in a deciduous forest that has a single leaf-fall season (Neumann et al. 1989, Cutini et al. 1998, Eriksson et al. 2005, Ishihara \& Hiura 2011). Recently, the annual maximum LAI of evergreen conifer forests with continuous leaf fall over years has been obtained by combining the annual litter fall values with the average life span of evergreen needles (Sprintsin et al. 2011, Guiterman et al. 2012, Reich et al. 2012). However, litter collection is more laborious in comparison to indirect methods, especially for collecting and sorting the litter fall termly.

Indirect inference of LAl is based on the gap fraction or gap size distribution within a canopy using radiative transfer theories (Ross 1981). Therein, digital hemispherical photography (DHP) and LAl-2000 plant canopy analyzer are the most widely used techniques for simultaneous measure- 
ments of the canopy structural characteristics from several zenith angles. However, the accuracy of the LAl from optical methods has typically been assessed using direct estimation of the LAI because the woody materials and foliage clumping effects (including beyond and within shoots) have also been identified as important issues associated with the use of these optical techniques in the field (Chen 1996, Chen et al. 1997, Chianucci et al. 2014, Lopes et al. 2014). For this reason, the effective LAI $\left(L_{\mathrm{e}}\right)$ has been proposed to describe optically derived LAl estimates in the literature (Chen \& Black 1992). Additionally, recent studies reported that an incorrect exposure setting in DHP LAl estimation may be a significant source of error (Chen et al. 1991, Cescatti 2007, Chianucci \& Cutini 2012, Beckschäfer et al. 2013, Song et al. 2013) by decreasing the contrast between the sky and foliage, further affecting the calculation of the LAI by DHP. Comparisons of the LAl estimated from DHP and the LAl-2000 techniques with those obtained from direct measurements have often been reported (Dufrêne \& Bréda 1995, Chen et al. 1997, Thimonier et al. 2010, Mason et al. 2012, Olivas et al. 2013). However, the accuracy of the $L_{\mathrm{e}}$ from DHP or LAl-2000 after correction for woody materials and clumping effects has rarely been evaluated based on nondestructive direct methods in different mixed deciduous-evergreen (i.e., deciduous broadleaf and evergreen needleleaf) and deciduous needleleaf forest stands.

In the present study, we directly estimated the LAl using a litter collection method in five different temperate forest stands in China, and these directly measured LAI values were used as a basis for validating optical measurements of LAI in the same sites. Our specific objectives were: (1) to evaluate the accuracy of the $L_{\mathrm{e}}$ derived from the DHP and LAl-2000 methods in different forest stands; (2) to quantify the relative contributions of dif- ferent sources of errors (e.g., woody materials, clumping effects within a canopy or automatic exposure) to LAl estimates by optical methods; and (3) to develop correlations between the optically determined $L_{\mathrm{e}}$ and the litter collection LAI, and examine whether these relationships are improved after considering the other canopy structural factors (e.g., woody materials and the clumping effects within a canopy) in estimating the LAl using the optical methods.

\section{Study site}

The study site is in the Liangshui National Nature Reserve, in northeastern China ( $47^{\circ}$ $\left.10^{\prime} 50^{\prime \prime} \mathrm{N}, 128^{\circ} 53^{\prime} 20^{\prime \prime} \mathrm{E}\right)$. The site is characterized by a rolling mountainous terrain, ranging from 300 to $707.4 \mathrm{~m}$ a.s.l. with a typical slope of $10^{\circ}-15^{\circ}$. The mean annual air temperature is $-0.3{ }^{\circ} \mathrm{C}$, and the mean annual rainfall is $676 \mathrm{~mm}$. The area has a long history of community development with a variety of forest stands. These forests mainly include mixed broadleavedKorean pine (Pinus koraiensis) forest (BK), selection cutting forest (SC), secondary birch (Betula platyphylla) forest (SB), Korean pine plantation (KP) and Dahurian larch (Larix gmelinii) plantation (DL). SC is derived from the Korean pine, where large $\mathrm{DBH}$ were cut in the $\mathrm{BK}$ that grew originally approximately 35 years ago; SB, KP and DL are forests developed on the harvested sites where BK grew originally. Specific information about the forest stands in this study is summarized in Tab. 1 .

Both $\mathrm{BK}$ and $\mathrm{SB}$ had one sampling plot $(60 \times 60 \mathrm{~m}) . \mathrm{SC}, \mathrm{KP}$ and DL all had three sampling plots $(20 \times 30 \mathrm{~m})$. Twenty litter traps were set randomly in both BK and SB plots. For SC, KP and $\mathrm{DL}$, each plot was divided into $10 \times 10 \mathrm{~m}$ subplots, and 6 litter traps were separately installed at the center of each subplot (i.e., a total of 18 litter traps for each forest stand). Each litter trap

\section{Materials and methods}

had a 0.5 or $1.0 \mathrm{~m}^{2}$ square aperture, and its base was approximately $0.5 \mathrm{~m}$ above the ground.

\section{Litter collection leaf area index}

Litterfall was collected monthly in each plot in 2013. Data collected in fall-winter were used for calculation of LAI in deciduous species, while data collected annually were used for calculation of LAl in evergreen species. In addition, we assumed that the new LAl for evergreen species is the same each year, a measurement of LAI in any year representing the average condition. Therefore, the LAI of evergreen species was obtained from multiplying the LAI from the litterfall within a certain period (one year) by the average life span of each species. The measurement of LAl at the plot was then obtained by summing such LAls for all the major species.

SLA for major species and the average life span for evergreen species were essential for estimating LAI using litter collection. In the present study, the SLA for major species was measured once a month from August to November in 2012. The experimental details and SLA values reported by Liu et al. (2014), and the mean SLA values over different periods were used to estimate LAl for major species in the litter collection method. It is worth noting that SLA can change along with falling of the leaves, thus the SLAs for major species were corrected using a shrinkage coefficient (ranging from 3.5 to $8.0 \%$ ) estimated from a sub-sample of green leaves collected in the study forest plots. Potential interannual variability in the SLA was considered negligible. The average life span for Pinus koraiensis, Abies nephrolepis and Picea spp. was 3.07, 3.69 and 3.91 years, respectively (Liu et al. 2014).

\section{Optical leaf area index}

The effective LAI, $L_{\mathrm{e}}$ can be usually measured using a DHP technique and LAl-2000 instruments based on the Miller (1967) theory (Chen 1996 - eqn. 1):

$$
L_{e}=2 \int_{0}^{\pi / 2} \ln \left[\frac{1}{P(\theta)} \cos \theta \sin \theta d \theta\right]
$$

gation in China.

\begin{tabular}{|c|c|c|c|c|c|c|}
\hline Forest stands & Major species & 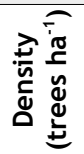 & 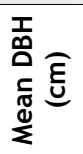 & 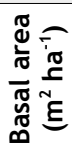 & $\begin{array}{l}\text { Land-use } \\
\text { history }\end{array}$ & 总怘 \\
\hline $\begin{array}{l}\text { Mixed broad- } \\
\text { leaf-Korean } \\
\text { pine forest }\end{array}$ & $\begin{array}{l}\text { Pinus koraiensis, Acer } \\
\text { mono, Tilia amurensis, } \\
\text { Betula costata }\end{array}$ & 2373 & 7.4 & 42.3 & Virgin forest & $>300$ \\
\hline $\begin{array}{l}\text { Selection } \\
\text { cutting forest }\end{array}$ & $\begin{array}{l}\text { Pinus koraiensis, Betula } \\
\text { costata, Fraxinus } \\
\text { mandshurica, Ulmus } \\
\text { japonica }\end{array}$ & 2010 & 8.7 & 26.9 & $\begin{array}{l}\text { Selection cutting } \\
\text { in virgin forest in } \\
1980 \mathrm{ca} \text {. }\end{array}$ & 35 \\
\hline $\begin{array}{l}\text { Secondary } \\
\text { birch forest }\end{array}$ & $\begin{array}{l}\text { Betula platyphylla, Larix } \\
\text { gmelinii, Picea spp. }\end{array}$ & 2854 & 7.2 & 23 & $\begin{array}{l}\text { Regeneration } \\
\text { forest after clear } \\
\text { cutting in } 1953\end{array}$ & 61 \\
\hline $\begin{array}{l}\text { Korean pine } \\
\text { plantation }\end{array}$ & $\begin{array}{l}\text { Pinus koraiensis, Betula } \\
\text { platyphylla, Larix gmelinii }\end{array}$ & 1973 & 11.5 & 33.3 & $\begin{array}{l}\text { Afforestation in } \\
1954\end{array}$ & 60 \\
\hline $\begin{array}{l}\text { Dahurian larch } \\
\text { plantation }\end{array}$ & $\begin{array}{l}\text { Larix gmelinii, Fraxinus } \\
\text { mandshurica, Acer mono }\end{array}$ & 1506 & 8.6 & 30.2 & $\begin{array}{l}\text { Afforestation in } \\
1954\end{array}$ & 60 \\
\hline
\end{tabular}

where $P(\theta)$ is the measured canopy gap fraction at the zenith angle $\theta$, which is the best when averaged over the entire azimuthal angle range.

\section{DHP measurements}

All hemispherical photographs were collected using a digital camera (Coolpix 4500 , Nikon, Tokyo, Japan), with a $180^{\circ}$ fisheye lens (Nikon FC-E8) in mid-July 2013. The camera was held $1.3 \mathrm{~m}$ above the ground using a tripod. All of the photographs were taken under an evenly overcast sky. We chose the following settings for the camera: (1) aperture priority mode with aperture set at $\mathrm{F} 5.3$ (i.e., automatic exposure); (2) high image quality $(2272 \times$ 1704 pixels); and (3) fine JPEG format. The 
photographs were processed with the DHP software to derive the $L_{\mathrm{e}}$ (Leblanc et al. 2005). A circular photograph was divided into concentric 6 rings spanning the zenith angle range from $0^{\circ}$ to $90^{\circ}$ (i.e., ring 1: $0^{\circ}$ $15^{\circ}$; ring $2: 15^{\circ}-30^{\circ}$; ring $3: 30^{\circ}-45^{\circ}$; ring $4: 45^{\circ}-$ $60^{\circ}$; ring 5: $60^{\circ}-75^{\circ}$; ring $\left.6: 75^{\circ}-90^{\circ}\right)$, but according to LAl-2000 measurements, $0^{\circ}$ $75^{\circ}$ (i.e., 1-5 rings) zenith angle ranges was selected to derive $L_{\mathrm{e}}$ and the Gamma function was set to 1 (Chianucci \& Cutini 2012).

\section{LAl-2000 measurements}

Canopy gap fraction and $L_{\mathrm{e}}$ were also estimated with LAl-2000 measurements (Licor Inc., Lincoln, NE, USA) at five concentric rings (ring $1: 0^{\circ}-13^{\circ}$; ring $2: 16^{\circ}-28^{\circ}$; ring $3: 32^{\circ}$ $43^{\circ}$; ring $4: 47^{\circ}-58^{\circ}$; ring $5: 61^{\circ}-74^{\circ}$ ), with the same time and location as hemispherical photographs. A LAl-2000 unit was subsequently operated at the same photographic spots for comparison with DHP, and the second LAI-2000 unit, cross-calibrated with the former, was used to automatically record "above-canopy" readings from a nearby clearing. A $90^{\circ}$ view cap was used on both units to avoid the influence of the operator on the sensor. The LAI-2000 data were processed using the available C2000 software for $L_{\mathrm{e}}$ within all five rings.

\section{Correction of optical LAl estimates}

The error of optical estimated LAl caused by woody materials and clumping effects within canopies has often been realized (Chen et al. 1997, Ryu et al. 2010, Chianucci \& Cutini 2012). Therefore, the following parameters should be considered in order to obtain a more accurate LAI (denoted as $L$ ) based on $L_{\mathrm{e}}$ (Chen et al. 1997 - eqn. 2):

$$
L=(1-\alpha) L_{e} \frac{\gamma_{E}}{\Omega_{E}}
$$

where $\alpha$ is the woody-to-total area ratio representing the woody materials (quantified by the woody area index, WAI) contribution to $L_{\mathrm{e}} ; L_{\mathrm{e}}$ is the effective LAl from optical instruments (DHP or LAl-2000); $\Omega_{\mathrm{E}}$ is the clumping index quantifying the effect of foliage clumping at scales larger than shoots; and $\gamma_{\mathrm{E}}$ is the needle-to-shoot area ratio quantifying the effect of foliage clumping within shoots. For broadleaf species, individual leaves are considered foliage elements, thus $\gamma_{E}=1.0$, but for needleleaf species, $\gamma_{E}$ is usually larger than 1.o. The caveat of these parameters (i.e., $\alpha$, $\Omega_{\mathrm{E}}$ and $\gamma_{\mathrm{E}}$ ) in eqn. 2 were measured only once, i.e., the same parameters were used to correct $L_{\mathrm{e}}$ derived from both DHP and LAl-2000.

\section{Woody-to-total area ratio (a)}

In this study we measured the $\alpha$ value using the Adobe Photoshop ${ }^{\oplus}$ (PS) software package (Qi et al. 2013). For mixed deciduous-evergreen forest stands (i.e., BK, SC, SB and KP), we first obtained the $L_{\mathrm{e}}$ of a photograph using the DHP software. Second, we replaced the green materials (mainly leaves and needles) with sky through the
"Clone Stamp Tool" of PS, leaving only woody materials visible (mainly stems) on the image. We could then obtain the WAI of the photograph by DHP with the same threshold as above. Finally, the parameter $\alpha$ was then derived accordingly ( $\alpha=$ WAI/ $L_{\mathrm{e}}$ ) in mixed deciduous-evergreen forest stands. For the deciduous forest stand (DL), we used a background method to remove the influence of woody materials on the optical estimation of LAI. Generally, the $W A I$ is the summation of stem area index (SAI) and branch area index (BAI). In this study, we ignored the contribution of the BAI to the LAI. First, we collected photographs at each sample point in DL during a leafless period (May $1^{\text {st }}$ ). Second, we separated the stems from woody materials using the "Clone Stamp Tool" in PS, similar to the process in mixed deciduous-evergreen forests, replacing the branches with sky. Finally, we obtained the $\alpha$ value for DL. It is worth noting that using the above procedure the WAI only represents the stem area index.

\section{Element clumping index $\left(\Omega_{\mathrm{E}}\right)$}

The $\Omega_{\mathrm{E}}$ was computed based on the gap size and fraction analysis (Chen \& Cihlar 1995, Leblanc et al. 2005 - eqn. 3):

$$
\Omega_{E}(\theta)=\frac{\ln \left[F_{m}(0, \theta)\right]\left[1-F_{m r}(0, \theta)\right]}{\ln \left[F_{m r}(0, \theta)\right]\left[1-F_{m}(0, \theta)\right]}
$$

where $F_{\mathrm{m}}(0, \theta)$ is the measured accumulated gap fraction larger than zero (i.e., the canopy gap fraction), and $F_{\mathrm{mr}}(0, \theta)$ is the gap fraction for the canopy when large gaps that are not theoretically possible in a random canopy have been removed for a given LAI and foliage element width. The advantage of this method to derive $\Omega_{\mathrm{E}}$ is that it can be applied to all types of plant canopies without the need for spatial pattern assumptions about canopy elements (Gonsamo \& Pellikka 2009). The $\Omega_{\mathrm{E}}$ values were measured by DHP-TRAC software (Chen et al. 2006, Macfarlane et al. 2007) within the zenith angle range $0-75^{\circ}$.

\section{Needle-to-shoot area ratio $\left(\gamma_{\mathrm{E}}\right)$}

The $\gamma_{E}$ for the four needleleaf species (Pinus koraiensis, Abies nephrolepis, Picea spp. and Larix gmelinii) in the five forest stands was quantified using destructive sampling in the field. For each needleleaf species, 27 shoot samples were taken from three trees: one dominant $(D, D B H \geq 40$ $\mathrm{cm})$, one co-dominant $(\mathrm{M}, 2 \mathrm{O} \leq \mathrm{DBH}<40$ $\mathrm{cm})$ and one suppressed (S, DBH $<20 \mathrm{~cm}$ ). Samples were collected at three heights for each tree: top $(\mathrm{T})$, middle $(\mathrm{M})$ and low $(\mathrm{L})$, creating nine classes containing three shoot samples each: DT, DM, DL, MT, MM, ML, ST, SM, and SL. These sample shoots were analyzed according to the volume replacement method proposed by Chen (1996), and the implementation details are reported in Liu et al. (2012). Finally, the $\gamma_{E}$ in a plot was obtained by weighting the $\gamma_{\mathrm{E}}$ of the trees of different species (both broad- leaf and needleleaf species) by their relative contribution to the total basal area in the plot.

In comparison to the LAl-2000 instrument, the accuracy of LAI measured using DHP is affected by the additional issue of photograph exposure setting. Therefore, we additionally corrected a systematic error in the DHP method due to incorrect automatic exposure (defined as $E$ ), based on the relationship between the DHP $L_{\mathrm{e}}$ obtained by automatic exposure and LAI$2000 L_{\mathrm{e}}$ reported by Zhang et al. (2005), i.e., $y=0.5611 \cdot x+0.3586\left(R^{2}=0.77\right)$, where $x$ is the $L_{e}$ estimated by LAl-2000, and $y$ is the $L_{\mathrm{e}}$ estimated by DHP within automatic exposure.

\section{Bias analysis}

For the DHP method, the sources of bias of LAI measurement were caused by $\alpha, \Omega_{\mathrm{E}}$, $\gamma_{\mathrm{E}}$, and $E$, thus, LAI $=f_{\mathrm{DHP}}\left(\alpha, \Omega_{\mathrm{E}}, \gamma_{\mathrm{E}}, E\right)$. Then, we calculated the total bias ( $\triangle L A I-$ eqn. 4):

$$
\begin{aligned}
\Delta L A I & =\frac{\partial L A I}{\partial \alpha} \Delta \alpha+\frac{\partial L A I}{\partial \Omega_{E}} \Delta \Omega_{E}+ \\
& +\frac{\partial L A I}{\partial \gamma_{E}} \Delta \gamma_{E}+\frac{\partial L A I}{\partial E} \Delta E
\end{aligned}
$$

where $\Delta \alpha=0-\alpha, \Delta \Omega_{\mathrm{E}}=1-\Omega_{\mathrm{E}}, \Delta \gamma_{\mathrm{E}}=1-\gamma_{\mathrm{E}}$ and $\Delta E=1-E$. For the LAl-2000 method, the sources of bias of LAI measurement were caused by $\alpha, \Omega_{\mathrm{E}}$, and $\gamma_{\mathrm{E}}$, thus, LAI $=f_{\text {LAl-200O }}(\alpha$, $\left.\Omega_{\mathrm{E}}, \gamma_{\mathrm{E}}\right)$. Then we calculated the total bias (eqn. 5):

$$
\Delta L A I=\frac{\partial L A I}{\partial \alpha} \Delta \alpha+\frac{\partial L A I}{\partial \Omega_{E}} \Delta \Omega_{E}+\frac{\partial L A I}{\partial \gamma_{E}} \Delta \gamma_{E}
$$

Therein the calculation of $\Delta \alpha, \Delta \Omega_{\mathrm{E}}$ and $\Delta \gamma_{\mathrm{E}}$ were the same as in eqn. 4 .

\section{Results}

\section{Gap fraction estimation by optical methods}

Generally, gap fraction measured by both DHP and LAl-2000 decreased with increasing zenith angle in different forest stands (Fig. 1), although DHP gave larger gap fraction values than that of LAI-2000, probably because of the incorrect automatic exposure set in DHP.

\section{Parameters for correcting optical LAI}

All parameters required for LAl correction using eqn. 2 are summarized in Tab. 2. The woody-to-total area ratio $(\alpha)$ ranged from $3 \%$ to $8 \%$ in five forest stands. The clumping effects beyond shoots $\left(\Omega_{\mathrm{E}}\right)$ varied slightly with the forest stand; the largest $\Omega_{\mathrm{E}}$ was 0.92 in DL, and KP had the smallest $\Omega_{\mathrm{E}}$ with a value of 0.89 . The KP had the largest clumping effects within the shoots $\left(\gamma_{\mathrm{E}}\right)$ with a value of 1.46. The $\gamma_{E}$ for SB (with a value of 1.08) was lower than that obtained for the other four forest types, because the large proportion of broadleaf species increased the weight of $\gamma_{E}$ for these species $\left(\gamma_{E}=1.0\right)$ in the overall $\gamma_{E}$ calculated for the whole forest stand. 

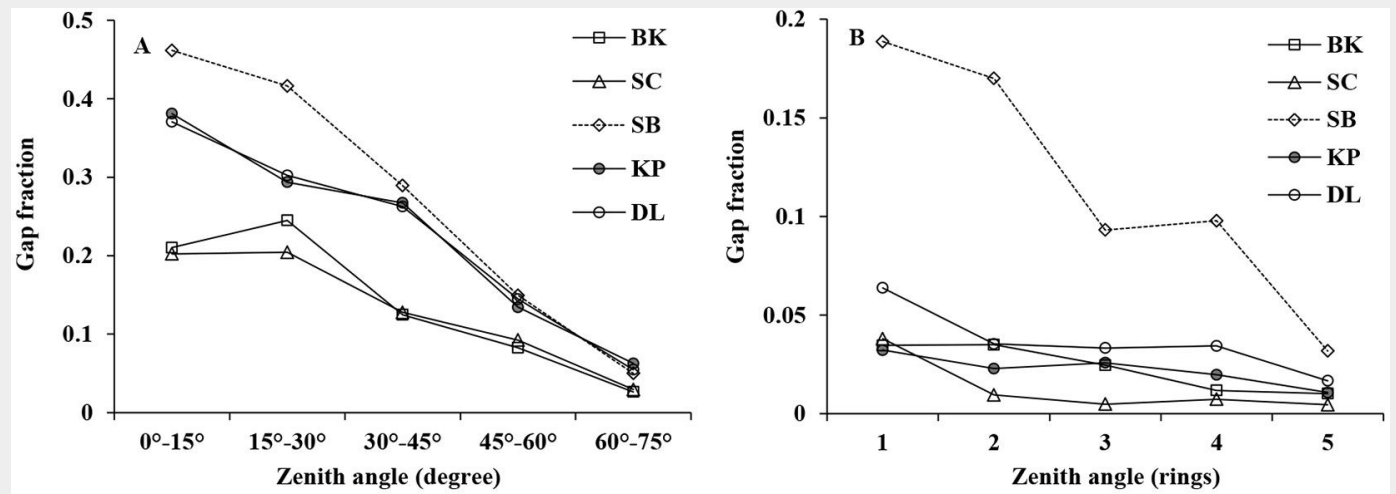

Fig. 1 - Gap fraction comparison among $\operatorname{DHP}(\mathrm{A})$ and $\mathrm{LAl}-2000$ (B) in five forest stands.

Tab. 2 - Correction factors for woody-to-total area ratio $(\alpha)$, clumping index $\left(\Omega_{\mathrm{E}}\right)$ and needle-to-shoot area ratio $\left(\gamma_{\mathrm{E}}\right)$ on optical LAI in five forest stands. (BK): mixed broadleaved-Korean pine forest; (SC): selection cutting forest; (SB): secondary birch forest; (KP): Korean pine plantation; (DL): Dahurian larch plantation.

\begin{tabular}{llllll}
\hline Factors & BK & SC & SB & KP & DL \\
\hline$\alpha(\%)$ & 4 & 3 & 5 & 5 & 8 \\
$\Omega_{\mathrm{E}}$ & 0.90 & 0.91 & 0.91 & 0.89 & 0.92 \\
$\gamma_{\mathrm{E}}$ & 1.41 & 1.28 & 1.08 & 1.46 & 1.27 \\
\hline
\end{tabular}

Tab. 3 - Comparison of the LAI from litter collection and optical (DHP and LAI-2000) methods in five forest stands. Means \pm standard deviations are reported. ( $L A I_{\text {lit }}$ ): LAI from litter collection; (DHP $L_{\mathrm{e}}$ ): effective LAI derived from the DHP method; $\left(L A I_{\mathrm{DHP}-\mathrm{C}}\right)$ : DHP $L_{\mathrm{e}}$ after correction for automatic exposure, woody materials and clumping effects within canopies; (LAI-2000 $L_{\mathrm{e}}$ ): effective LAl derived from the LAl-2000 method; $\left(L A I_{2000-c}\right)$ : represents $\mathrm{LAl}-2000 \mathrm{~L}_{\mathrm{e}}$ after correction for woody materials and clumping effects within canopies.

\begin{tabular}{lccccc}
\hline Forest Type & $\boldsymbol{L} \boldsymbol{A} \boldsymbol{I}_{\text {lit }}$ & DHP $\boldsymbol{L}_{\mathrm{e}}$ & $\boldsymbol{L} \boldsymbol{A} \boldsymbol{I}_{\text {DHP-C }}$ & LAI-2000 $\boldsymbol{L}_{\mathrm{e}}$ & $\boldsymbol{L} \boldsymbol{A} \boldsymbol{I}_{2000-\mathrm{C}}$ \\
\hline BK & $8.84 \pm 1.04$ & $3.05 \pm 0.18$ & $8.81 \pm 0.78$ & $5.28 \pm 0.85$ & $8.33 \pm 1.35$ \\
SC & $9.42 \pm 0.66$ & $2.99 \pm 0.36$ & $6.82 \pm 0.83$ & $6.82 \pm 0.77$ & $9.31 \pm 1.05$ \\
SB & $3.69 \pm 0.48$ & $1.96 \pm 0.12$ & $3.47 \pm 0.21$ & $3.11 \pm 0.41$ & $3.57 \pm 0.48$ \\
KP & $7.95 \pm 1.07$ & $2.33 \pm 0.19$ & $6.09 \pm 0.50$ & $5.12 \pm 1.04$ & $8.56 \pm 1.11$ \\
DL & $5.59 \pm 1.13$ & $2.21 \pm 0.29$ & $4.69 \pm 0.70$ & $4.23 \pm 1.43$ & $5.43 \pm 1.03$ \\
\hline
\end{tabular}

Comparison of the LAI from direct and indirect methods

Based on the litter collection, the SC had the largest $\mathrm{LAI}$, with a value of $9.42 \pm 0.66$ (SD), followed by BK, KP, DL and SB, with values of $8.84 \pm 1.04,7.95 \pm 1.07,5.59 \pm 1.13$ and $3.69 \pm 0.48$, respectively (Tab. 3 ). Ge- ference between DHP $L_{\mathrm{e}}$ and $L A I_{\text {lit }}$ are af- fected by the species composition of forest stands. However, the accuracy of DHP $L_{\mathrm{e}}$ after correcting for the woody materials, clumping effects within canopies and incorrect exposure was greatly improved in all forest stands. The difference between the $L A I_{\text {lit }}$ and the corrected LAl from DHP was $1 \%, 2 \%$ and $12 \%$ in BK, SB and DL, respectively (Tab. 3, Fig. 2). However, the corrected LAI from DHP still underestimated $L A I_{\text {lit }}$ by $17 \%$ and $21 \%$ on average for $S C$ and $K P$, respectively. In contrast, LAl-2000 $L_{\mathrm{e}}$ underestimated $L A I_{\text {lit }}$ by $40 \%, 27 \%, 13 \%, 36 \%$ and $21 \%$ on average for $\mathrm{BK}, \mathrm{SC}, \mathrm{SB}, \mathrm{KP}$ and $\mathrm{DL}$, respectively. The accuracy of the LAl-2000 $L_{\mathrm{e}}$ after correction for woody materials and clumping effects within canopies markedly improved in all five forest stands. The difference between the $L A I_{\text {lit }}$ and corrected LAI from LAl-2000 was less than $7 \%$ in all forest stands (Fig. 2), indicating that the correction scheme for LAI-2000 is reasonable and effective not only in deciduous but also mixed deciduous-evergreen forest stands. It is worth noting that the corrected LAI from the optical method showed larger LAI values than $L A I_{\text {lit }}$ in some forest stands. After correcting LAI from DHP, average overestimation was only $1 \%$ for $B K$, while it was lower than $7 \%$ for SB, KP and DL after correcting LAl from LAl-2000, based on comparison with $L A I_{\text {lite }}$.

Overall, the bias due to each factor varied with forest stands more than optical mea-

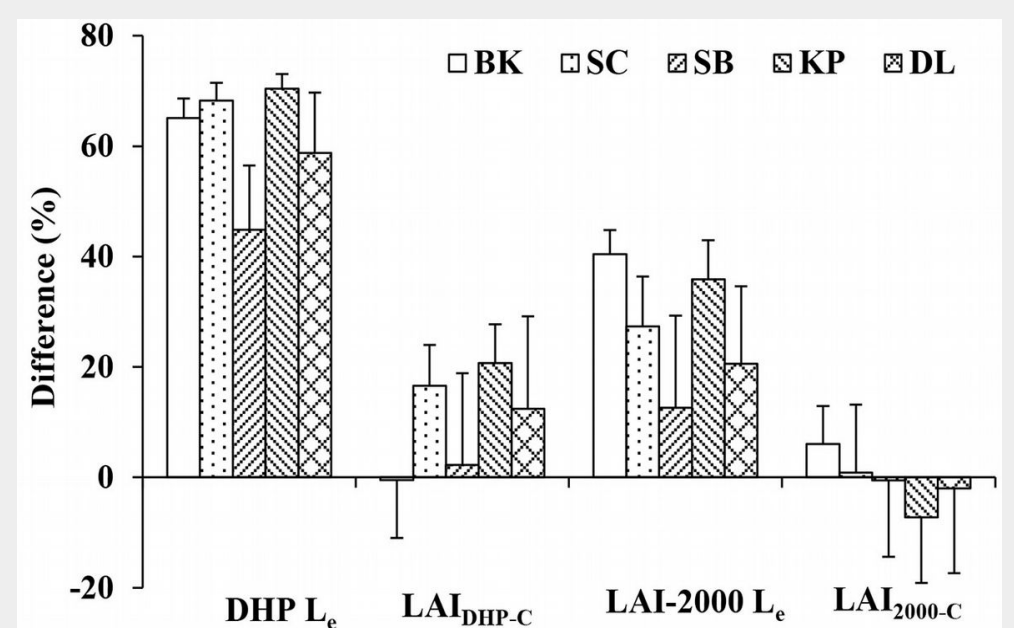

Fig. 2 - Differences between litter collection LAI and optical LAI (DHP and LAI-2000). All abbreviations are the same as in Tab. 2 . Difference $(\%)=\left(L A I_{\text {lit }}\right.$ optical $\mathrm{LAI}) / L A I_{\text {lit }} \times 100$. Optical LAI includes the effective and corrected LAI from DHP and LAl-2000.

Optical LAI 
Fig. 3 - The biases caused by woody-to-total area ratio $(\alpha)$, clumping index $\left(\Omega_{\mathrm{E}}\right)$, needleto-shoot area ratio $\left(\gamma_{\mathrm{E}}\right)$ or automatic exposure $(E)$ for optical LAI (DHP and LAl-2000) in five different forest stands.

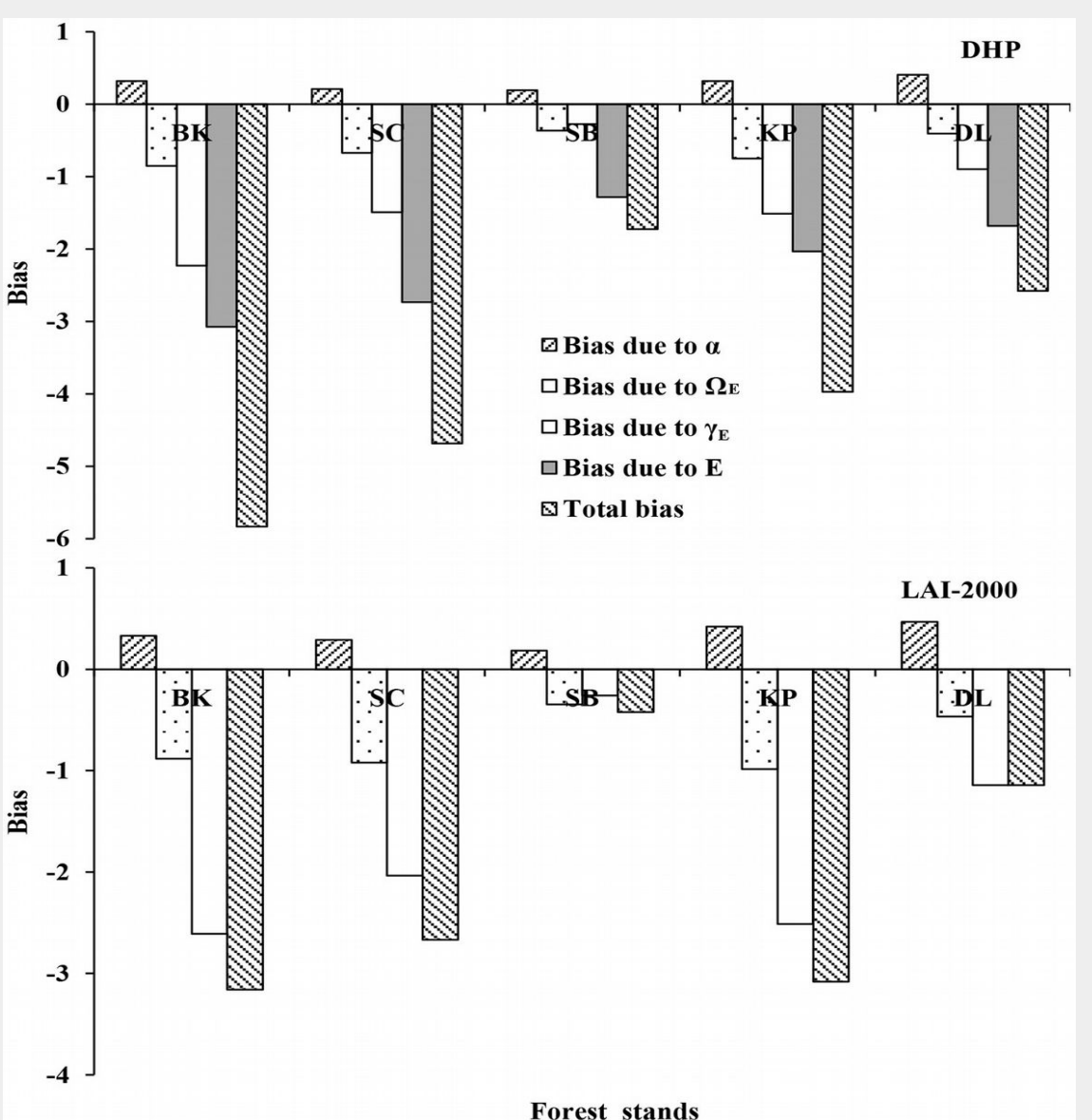

Forest stands surement (i.e., DHP and LAl-2000), and the contribution of $\alpha$ to optical $L_{\mathrm{e}}$ was opposite with other factors (e.g., $\Omega_{\mathrm{E}}, \gamma_{\mathrm{E}}$ or $E$ - Fig. 3). For DHP $L_{e}$, the absolute bias due to automatic exposure was largest in different forests, followed by that due to $\gamma_{\mathrm{E}}$. The total bias of DHP $L_{\mathrm{e}}$ due to all factors were $-5.83,-4.69,-1.72,-3.97$, and -2.58 for $\mathrm{BK}$, $\mathrm{SC}, \mathrm{SB}, \mathrm{KP}$, and $\mathrm{DL}$, respectively. In contrast, for LAl-2000 $L_{\mathrm{e}}$, the absolute bias due to $\gamma_{\mathrm{E}}$ was larger than those due to $\alpha$ and $\Omega_{\mathrm{E}}$ in most stands (except SB). For BK, SC, and $\mathrm{KP}$, the absolute biases of LAl-2000 $L_{\mathrm{e}}$ due to $\Omega_{\mathrm{E}}$ were larger than that of $\alpha$, but for SB and $\mathrm{DL}$, the biases of these factors showed different patterns. The total bias of LAI$2000 L_{\mathrm{e}}$ due to all factors were $-3.16,-2.66$, $-0.42,-3.08$, and -1.14 for BK, SC, SB, KP, and $\mathrm{DL}$, respectively.

Generally, the DHP method gave smaller $L_{\mathrm{e}}$ values than those obtained by LAI-2000
Tab. 4 - Correlation between litter collection LAI ( $\left.L A I_{\text {lit }}\right)$ and optical LAI (DHP and LAI2000). The expression used for regressions was $y=a x+b$. Coefficients of determination $\left(R^{2}\right)$, root mean squared errors (RMSE) and probability $(P)$ of the regressions were reported. $\left(^{*}\right)$ : regressions in which the intercept does not differ from zero and the slope does not differ from $1(p<0.05)$. All abbreviations in LAl formats are defined in Tab. 2.

\begin{tabular}{|c|c|c|c|c|c|}
\hline LAl formats ( $x$ vs.y) & a & b & $R^{2}$ & RMSE & $\boldsymbol{P}$ \\
\hline LAI-2000 $L_{\mathrm{e}}$ Vs. DHP $L_{\mathrm{e}}$ & 0.25 & 1.32 & 0.57 & 0.33 & $<0.01$ \\
\hline Corrected LAl from LAI-2000 vs. Corrected LAl from DHP & $0.56^{*}$ & 1.99 & 0.66 & 1.02 & $<0.01$ \\
\hline LAl from litter collection vs. DHP $L_{\mathrm{e}}$ & 0.18 & 1.23 & 0.79 & 0.23 & $<0.01$ \\
\hline LAI from litter collection vs. Corrected LAI from DHP & $0.69^{*}$ & $1.05^{*}$ & 0.76 & 0.98 & $<0.01$ \\
\hline LAl from litter collection vs. LAI-2000 $L_{\mathrm{e}}$ & $0.52^{*}$ & $1.07^{*}$ & 0.75 & 0.76 & $<0.01$ \\
\hline LAl from litter collection vs. Corrected LAl from LAI- 2000 & $0.90^{*}$ & $0.81^{*}$ & 0.83 & 1.04 & $<0.01$ \\
\hline
\end{tabular}

in all forest stand (Tab. 3, Fig. 4). DHP $L_{\mathrm{e}} \quad 2000 L_{\mathrm{e}}\left(R^{2}=0.57\right.$, RMSE $=0.33$ and $P<0.01$ underestimated LAl-2000 $L_{\mathrm{e}}$ by an average - Tab. 4). The correlation between DHP $L_{\mathrm{e}}$ of $42 \%, 56 \%, 37 \%, 54 \%$ and $48 \%$ for BK, SC, and LAl-2000 $L_{\mathrm{e}}$ was enhanced after correc$\mathrm{SB}, \mathrm{KP}$ and $\mathrm{DL}$, respectively. However, the ting for the parameters in eqn. 2 (Fig. 4), as DHP $L_{\mathrm{e}}$ significantly correlated with $\mathrm{LAl}$ - indicated by the increased $R^{2}$ value (0.66 -
Fig. 4 - Scatter analysis of the LAl estimated by the LAI2000 and DHP methods in five forest stands. The dotted line represents the 1:1 relationship.
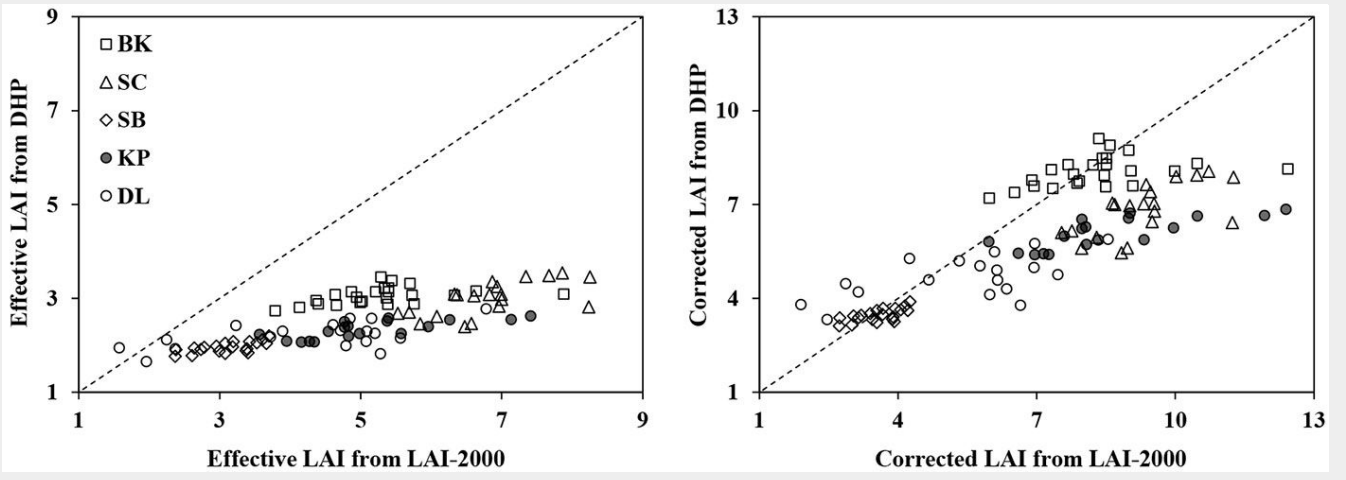

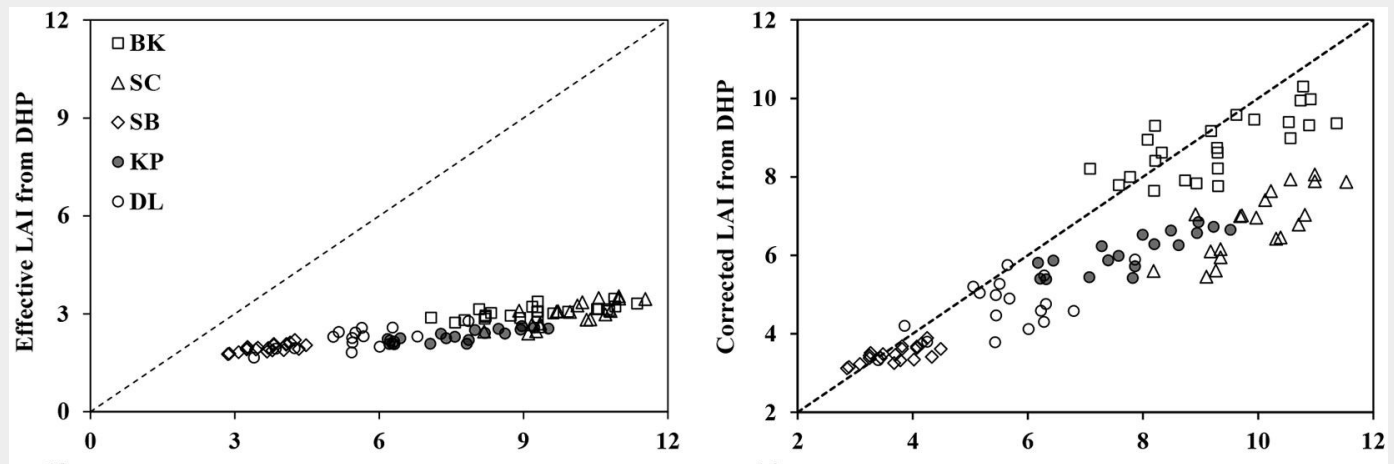

Fig. 5 - Scatter analysis of the LAl estimated by litter collection and optical methods (DHP and LAI2000) in five forest stands. Optical LAI includes effective and corrected LAl from DHP and LAl-2000. The dotted line indicates the 1:1 relationship.
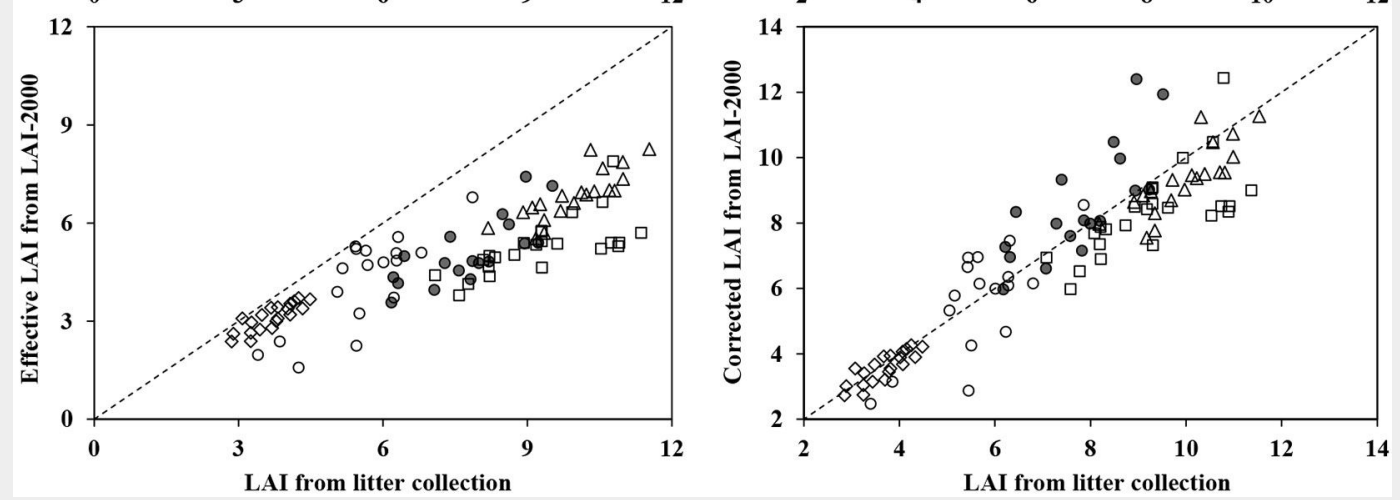

Tab. 4).

Fig. 5 illustrates the correlation between $L A I_{\text {lit }}$ and LAl from optical methods (both DHP and LAl-2000) in five different forest stands. A significant correlation $(P<0.01)$ between the $L A I_{\text {lit }}$ and uncorrected $L_{\mathrm{e}}$ obtained by optical methods was observed (Tab. 4), with $R^{2}=0.79$ and 0.75 , RMSE = 0.23 and 0.76 for DHP and LAl-2000, respectively. For DHP $L_{\mathrm{e}}$, the correction for woody materials, clumping effects and incorrect exposure setting did not improved the correlation with $L A I_{\text {lit }}$ clearly. In contrast, the correction scheme on LAI2000 was more effective, as indicated by the $R^{2}$ value of 0.83 . These results suggested that the error caused by woody materials and clumping effects within canopies (additional incorrect exposure for DHP) explained the majority of the error caused by estimating LAI by optical methods (e.g., DHP and LAI-2000).

\section{Discussion}

In this study optical methods (e.g., DHP and LAI-2000) gave lower LAI values than the litter collection method in different forest stands. DHP $L_{\mathrm{e}}$ underestimated $L A I_{\text {lit }}$ by 44-70\%, while underestimation ranged from $13 \%$ to $40 \%$ for LAI-2000 in these forest stands. Similar results have often been reported in previous studies. Jonckheere et al. (2005) reported that the LAl-2000 underestimated the directly estimated LAI by $52 \%$, and the underestimation for hemispherical photographs averaged $55 \%$. Mason et al. (2012) found that the LAl-2000 $L_{e}$ underestimated destructive sampling LAI in the range $30 \%$ to $60 \%$ in Pinus radiata plantations in New Zealand. Van Gardingen et al. (1999) found the DHP $L_{\mathrm{e}}$ underestimated the LAl by $50 \%$ relative to the har- vesting method in a canopy of Gliricidia sepium in Mexico. However, we found a significant correlation between directly measured LAI and optical LAl in different forest stands (Tab. 4, Fig. 5). Similar relationships have been reported in the majority of published studies in different forest stands, e.g., Cutini et al. (1998) in stands of the main broad-leaved forest species, Sonnentag et al. (2007) in shrubs, Mason et al. (2012) in Pinus radiata plantations and Chianucci \& Cutini (2013) in different deciduous forests.

The error in the estimation of LAl by optical techniques was mainly caused by woody materials and clumping effects within canopies. However, correcting for the clumping effects results in higher LAI values than the $L_{\mathrm{e}}$ values alone, while correcting for the woody materials only gave lower values (Fig. 3). The $\alpha$ value has been widely measured by direct or indirect methods in previous studies. For instance, based on a destructive sampling method in different boreal forest species, Gower et al. (1999) measured $\alpha$ values ranging from 0.05 to 0.35 . Deblonde et al. (1994) also reported $\alpha$ values of 0.08-0.12 for stands of Pinus resinosa by the direct method. However, this method is destructive and labor intensive, and too difficult to be used in the assessment of $\alpha$ values at a stand level. In contrast, the use of indirect techniques (e.g., DHP or LAl-2000) to estimate WAI in leafless periods and its subtractiion from the optical LAI in leafy periods is more practical. For example, Bréda (2003) investigated 70 oak stands during the leafless and leafy periods within a year, finding that $\alpha$ ranged from 0.07 to 0.40 . However, this method is only effective in deciduous forest stands since evergreen or mixed deci- duous-evergreen forests have no leafless periods. Additionally, previous results are larger than ours ( $\alpha$ in the scope of 0.03 0.08 ), probably because the seasonal variation of the contribution of woody materials to the LAI was not considered in most previous studies. Nevertheless, this contribution varies with the season as the expanded leaves mask some woody materials (e.g., branches), especially in peak LAI period. Similar viewpoints have been reported. For instance, Dufrêne \& Bréda (1995) reported that during the full-leaf period (as in this study), only stems accounted for the WAI. Kucharik et al. (1998) also reported that branches generally do not significantly bias indirect LAI measurements, but the stems may not be preferentially shaded by leaves. These results provide theoretical support for the usage of the PS software for an effective quantification of the visible stem area. In addition, if the WAI was directly subtracted from the optical LAl in leafy periods in DL forest stands (deciduous forest), the error caused by woody materials was overestimated by $32 \%$ and $21 \%$ for DHP and LAI-2000, respectively. Therefore, it is very necessary to consider the seasonal changes of the contribution of woody materials in correcting the optically estimated LAI in further research.

As for a needleleaf forest stands, the clumping effects within canopies can be grouped into two levels, the clumping effects beyond (corrected by $\Omega_{\mathrm{E}}$ ) and within shoots (corrected by $\gamma_{\mathrm{E}}$ ). The determination of $\Omega_{\mathrm{E}}$ by DHP-TRAC has been previously recommended (Leblanc et al. 2005, Chen et al. 2006, Macfarlane et al. 2007). In this study, $\Omega_{\mathrm{E}}$ ranged from 0.89 to 0.92 in different forest stands. Similar results have 
been reported in the majority of published studies in different forest stands. Chen et al. (2006) reported that the $\Omega_{\mathrm{E}}$ values ranged from 0.88 to 0.96 by DHP-TRAC in different forest types. To date, measurement of the $\gamma_{\mathrm{E}}$ values often relies heavily on the destructive sampling method in the field. In the present study, $\gamma_{E}$ ranged from 1.08 to 1.46 , primarily depending on the relative abundance of broadleaf and needleleaf species in the stand. Similar values were reported by Chen (1996) for six black spruce (Picea mariana) and jack pine (Pinus banksiana) stands $\left(\gamma_{\mathrm{E}}=1.48\right)$ and by Kucharik et al. (1998) for coniferous species ( $\gamma_{E}$ ranging from 1.2 to 2.0 ). Although the accuracy of the DHP LAI after correction for woody materials, clumping effects within canopies and automatic exposure was improved greatly, the corrected LAl from DHP underestimated the $L A I_{\text {lit }}$ by $21 \%$ in KP. In our opinion, such discrepancy is mainly due to the automatic exposure adopted, since the light level in KP is generally lower than in other forest stands because of the high proportion of evergreen needleleaf species. Indeed, such conditions may cause a LAI underestimation due to the automatic exposure larger than the exposure correction for the average light condition. In contrast, the difference between $L A I_{\text {lit }}$ and LAI-2000 $L_{\mathrm{e}}$ was less than $7 \%$ in different forest stands after considering the woody materials and clumping effects within canopies. This result indirectly supports the viewpoint reported by Chen et al. (1997), that optical measurements combined with shoot sample analysis can produce LAl values for conifer stands that are more accurate than destructive sampling results.

By contrast, the contribution of $\alpha$ and $\Omega_{\mathrm{E}}$ to optical LAl differed only slightly among forest stands, while a clear difference among different forest stands was detected for the contribution of $\gamma_{\mathrm{E}}$ to optical LAI (Fig. 3), probably because $\gamma_{\mathrm{E}}$ varies with species significantly. In addition, the contribution of $\alpha, \Omega_{\mathrm{E}}$ and $\gamma_{\mathrm{E}}$ to optical LAl differed significantly in most forest stands, except for SB, where needleleaf species are largely less abundant than broadleaf species, the latter accounting for $92 \%$ of the total basal area. Therefore, species composition of a forest stand should be given more attention when improving the accuracy of LAl estimated by optical methods in future studies.

A significant correlation between the LAI estimates by DHP and by LAl-2000 is shown in Fig. 4. Similar relationships have been reported in other studies, e.g., Martens et al. (1993) in a mixed conifer forest, Chen et al. (1997) in boreal forests and Thimonier et al. (2010) in 15 plots of the Swiss Long-Term Forest Ecosystem Research Programme. However, DHP $L_{\mathrm{e}}$ underestimated LAl-2000 $L_{\mathrm{e}}$ by an average of $37-56 \%$ (Tab. 3), probably because of the automatic exposure setting for DHP. Additionally, Fig. 3 showed that the largest uncertainty of
DHP $L_{\mathrm{e}}$ was the automatic exposure setting. Automatic exposure is used to create a certain brightness of the image; under low light conditions the exposure increases, causing overexposure of leaves that receive skylight at the top, and determining the underestimation of LAl using DHP. Zhang et al. (2005) reported that automatic exposure can cause $L_{\mathrm{e}}$ underestimations by $16-71 \%$ for medium- and high-density canopies. Therefore, not only the woody materials and clumping effects but also the correct exposure setting should be carefully considered estimating LAI using the DHP method in further research.

\section{Conclusions}

Based on litter collection, we directly estimated the LAI in four mixed deciduousevergreen forests and one deciduous needleleaf forest. The results were used to evaluate two conventional indirect optical methods (DHP and LAI-2000). Optical LAI was significantly correlated with litter collection LAI $(P<0.01)$. However, DHP $L_{e}$ underestimated $L A I_{\text {lit }}$ by an average of 44$70 \%$ depending on forest stand. These underestimations range for LAl-2000 were $13-40 \%$. Nevertheless, the difference between $L A I_{\text {lit }}$ and DHP $L_{\mathrm{e}}$ after correction for the effect of automatic exposure, woody materials and clumping effects was less than $21 \%$. In contrast, the accuracy of the best estimates of LAl using LAl-2000 was over $93 \%$ after considering woody materials and foliage clumping within shoots and the canopy in different forest stands, suggesting that this technique allows to estimate LAl accurately after careful correction. Additionally, the relative contribution of automatic exposure setting to the underestimation of LAI by the DHP technique is larger than other factors $\left(\alpha, \Omega_{\mathrm{E}, \text { and }}\right.$ $\gamma_{E}$ ) in all forest stands, and $\gamma_{E}$ has the biggest relative contribution to underestimation of LAl using the LAl-2000 instrument in most forest stands. Such results suggest that species composition of forest stand should also be considered in estimating LAI by optical methods in future studies.

\section{Acknowledgements}

We thank Jing $M$. Chen for the comments of the revised manuscript. We also would like to express our gratitude to the anonymous reviewers for their constructive and valuable comments on the manuscript. This work was financially supported by the Ministry of Science and Technology of China (No. 2011BAD37B01), National Natural Science Foundation of China (No. 31270473) and the Fundamental Research Funds for the Central Universities (2572014AA01).

\section{References}

Beckschäfer P, Seidel D, Kleinn C, Xu J (2013). On the exposure of hemispherical photographs in forests. iForest - Biogeosciences and Forestry 6: 228-237. - doi: 10.3832/iforo957-006

Beckschäfer P, Fehrmann L, Harrison R, Xu J,
Kleinn C (2014). Mapping leaf area index in subtropical upland ecosystems using RapidEye imagery and the random forest algorithm. iForest - Biogeosciences and Forestry 7: 1-11. - doi: 10.3832/iforo968-006

Bequet R, Kint V, Campioli M, Vansteenkiste D, Muys B, Ceulemans R (2012). Influence of stand, site and meteorological variables on the maximum leaf area index of beech, oak and Scots pine. European Journal of Forest Research 131: 283-295. - doi: 10.1007/s10342-011-05 oo-x

Bréda NJJ (2003). Ground-based measurements of leaf area index: a review of methods, instruments and current controversies. Journal of Experimental Botany 54: 2403-2417. - doi: 10.1093/ jxb/erg263

Cescatti A (2007). Indirect estimates of canopy gap fraction based on the linear conversion of hemispherical photographs: methodology and comparison with standard thresholding techniques. Agricultural and Forest Meteorology 143: 1-12. - doi: 10.1016/j.agrformet.2006.04.009 Chen JM (1996). Optically-based methods for measuring seasonal variation of leaf area index in boreal conifer stands. Agricultural and Forest Meteorology 80: 135-163. - doi: 10.1016/01681923(95)02291-0

Chen JM, Black TA (1992). Defining leaf area index for non-flat leaves. Plant, Cell and Environment 15: 421-429. - doi: 10.1111/j.1365-3040.19 92.tboog92.x

Chen JM, Black TA, Adams RS (1991). Evaluation of hemispherical photography for determining plant area index and geometry of a forest stand. Agricultural and Forest Meteorology 56: 129-143. - doi: 10.1016/0168-1923(91)90108-3 Chen JM, Cihlar J (1995). Quantifying the effect of canopy architecture on optical measurements of leaf area index using two gap size analysis methods. IEEE Transactions on Geoscience and Remote Sensing 33: 777-787. - doi: 10.1109/36.387593

Chen JM, Rich PM, Gower ST, Norman JM, Plummer S (1997). Leaf area index of boreal forests: theory, techniques, and measurements. Journal of Geophysical Research 102: 29429-29443. doi: 10.1029/97JD01107

Chen JM, Govind A, Sonnentag O, Zhang Y, Barr A, Amiro B (2006). Leaf area index measurements at Fluxnet-Canada forest sites. Agricultural and Forest Meteorology 140: 257-268. doi: 10.1016/j.agrformet.2006.08.005

Chianucci F, Cutini A (2012). Digital hemispherical photography for estimating forest canopy properties: current controversies and opportunities. iForest - Biogeosciences and Forestry 5: 290-295. - doi: 10.3832/iforo775-005

Chianucci F, Cutini A (2013). Estimation of canopy properties in deciduous forests with digital hemispherical and cover photography. Agricultural and Forest Meteorology 168: 130-139. doi: 10.1016/j.agrformet.2012.09.002

Chianucci F, Chiavetta U, Cutini A (2014). The estimation of canopy attributes from digital cover photography by two different image analysis methods. iForest - Biogeosciences and Forestry 7: 255-259. - doi: 10.3832/iforo939-007 Cutini A, Matteucci G, Mugnozza G (1998). Estimation of leaf area index with the Li-Cor LAI 2000 in deciduous forests. Forest Ecology and 
Management 105: 55-65. - doi: 10.1016/S03781127(97)00269-7

Deblonde G, Penner M, Royer A (1994). Measuring leaf area index with the LI-COR LAl-2000 in pine stands. Ecology 75: 1507-1511. - doi: 10.23 07/1937474

Dufrêne E, Bréda N (1995). Estimation of deciduous forest leaf area index using direct and indirect methods. Oecologia 104: 156-162. - doi: 10.1007/BFo0328580

Eriksson H, Eklundh L, Hall K, Lindroth A (2005) Estimating LAI in deciduous forest stands. Agricultural and Forest Meteorology 129: 27-37. doi: 10.1016/j.agrformet.2004.12.003

Gonsamo A, Chen JM (2014). Continuous observation of leaf area index at Fluxnet-Canada sites. Agricultural and Forest Meteorology 189: 168-174. - doi: 10.1016/j.agrformet.2014.01.016

Gonsamo A, Pellikka P (2009). The computation of foliage clumping index using hemispherical photography. Agricultural and Forest Meteorology 149: 1781-1787. - doi: 10.1016/j.agrformet.20 09.06 .001

Gower ST, Kucharik CJ, Norman JM (1999). Direct and indirect estimation of leaf area index, $f(A P A R)$, and net primary production of terrestrial ecosystems. Remote Sensing of Environment 70: 29-51. - doi: 10.1016/S0034-4257 (99)00056-5

Guiterman CH, Seymour RS, Weiskittel AR (2012). Long-term thinning effects on the leaf area of Pinus strobus $L$. as estimated from litterfall and individual-tree allometric models. Forest Science 58: 85-93. - doi: 10.5849/forsci.10-002

Ishihara MI, Hiura T (2011). Modeling leaf area index from litter collection and tree data in a deciduous broadleaf forest. Agricultural and Forest Meteorology 151: 1016-1022. - doi: 10.1016 /j.agrformet.2011.02.007

Jonckheere I, Muys B, Coppin P (2005). Allometry and evaluation of in situ optical LAI determination in Scots pine: a case study in Belgium. Tree physiology 25: 723-732. - doi: 10.1093/tree phys/25.6.723

Jonckheere I, Fleck S, Nackaerts K, Muys B, Coppin $P$, Weiss $M$, Baret $F$ (2004). Review of methods for in situ leaf area index determination: Part I. Theories, sensors and hemispherical photography. Agricultural and Forest Meteorology 121: 19-35. - doi: 10.1016/j.agrformet.2003. 08.027

Kucharik CJ, Norman JM, Gower ST (1998). Measurements of branch area and adjusting leaf area index indirect measurements. Agricultural and Forest Meteorology 91: 69-88. - doi: 10.1016/S0168-1923(98)00064-1

Leblanc SG, Chen JM, Fernandes R, Deering DW, Conley A (2005). Methodology comparison for canopy structure parameters extraction from digital hemispherical photography in boreal forests. Agricultural and Forest Meteorology 129: 187-207. - doi: 10.1016/j.agrformet.2004.09. 006

Liu ZL, Jin GZ, Chen JM, Qi YJ (2014). Evaluating optical measurements of leaf area index against litter collection in a mixed broadleavedKorean pine forest in China. Trees - Structure and Function 29: 59-73. - doi: 10.1007/s00468014-1058-2

Liu ZL, Jin GZ, Qi YJ (2012). Estimate of leaf area index in an old-growth mixed broadleavedkorean pine forest in northeastern china. PLoS One 7: e32155. - doi: 10.1371/journal.pone.0032 155

Lopes D, Nunes L, Walford N, Aranha J, Sette C, Viana H, Hernandez C (2014). A simplified methodology for the correction of leaf area index (LAl) measurements obtained by ceptometer with reference to Pinus Portuguese forests. iForest - Biogeosciences and Forestry 7 : 186-192. - doi: 10.3832/iforo096-007

Macfarlane C, Hoffman M, Eamus D, Kerp N, Higginson S, McMurtrie R, Adams M (2007). Estimation of leaf area index in eucalypt forest using digital photography. Agricultural and Forest Meteorology 143: 176-188. - doi: 10.1016/j. agrformet.2006.10.013

Martens SN, Ustin SL, Rousseau RA (1993). Estimation of tree canopy leaf area index by gap fraction analysis. Forest Ecology and Management 61: 91-108. - doi: 10.1016/0378-1127(93)901 92-P

Mason EG, Diepstraten M, Pinjuv GL, Lasserre J-P (2012). Comparison of direct and indirect leaf area index measurements of Pinus radiata D. Don. Agricultural and Forest Meteorology 166167: 113-119. - doi: 10.1016/j.agrformet.2012.06. 013

Miller JB (1967). A formula for average foliage density. Australian Journal of Botany 15: 141144. - doi: 10.1071/BT9670141

Neumann HH, Den Hartog G, Shaw RH (1989). Leaf area measurements based on hemispheric photographs and leaf-litter collection in a deciduous forest during autumn leaf-fall. Agricultural and Forest Meteorology 45: 325-345. doi: 10.1016/0168-1923(89)90052-X

Olivas PC, Oberbauer SF, Clark DB, Clark DA, Ryan MG, O'Brien JJ, Ordoñez H (2013). Comparison of direct and indirect methods for assessing leaf area index across a tropical rain forest landscape. Agricultural and Forest Meteorology 177: 110-116. - doi: 10.1016/j.agrformet.20 13.04.010

Qi YJ, Jin GZ, Liu ZL (2013). Optical and litter collection methods for measuring leaf area index in an old-growth temperate forest in northeastern China. Journal of Forest Research 18: 430-
439. - doi: 10.1007/s10310-012-0370-1 Reich PB, Frelich LE, Voldseth RA, Bakken P, Adair C (2012). Understorey diversity in southern boreal forests is regulated by productivity and its indirect impacts on resource availability and heterogeneity. Journal of Ecology 100: 539-545. - doi: 10.1111/j.1365-2745.2011.0192 2.x

Ross J (1981). The radiation regime and architecture of plant stands. Junk, The Hague, The Netherlands, pp. 391.

Ryu Y, Nilson T, Kobayashi H, Sonnentag O, Law BE, Baldocchi DD (2010). On the correct estimation of effective leaf area index: does it reveal information on clumping effects? Agricultural and Forest Meteorology 150: 463-472. - doi: 10.1016/j.agrformet.2010.01.009

Song G-ZM, Doley D, Yates D, Chao K-J, Hsieh C-F (2013). Improving accuracy of canopy hemispherical photography by a constant threshold value derived from an unobscured overcast sky. Canadian Journal of Forest Research 44: 1727. - doi: 10.1139/cjfr-2013-0082

Sonnentag O, Talbot J, Chen JM, Roulet NT (2007). Using direct and indirect measurements of leaf area index to characterize the shrub canopy in an ombrotrophic peatland. Agricultural and Forest Meteorology 144: 200-212. doi: 10.1016/j.agrformet.2007.03.001

Sprintsin M, Cohen S, Maseyk K, Rotenberg E, Grünzweig J, Karnieli A, Berliner P, Yakir D (2011). Long term and seasonal courses of leaf area index in a semi-arid forest plantation. Agricultural and Forest Meteorology 151: 565-574. doi: 10.1016/j.agrformet.2011.01.001

Thimonier A, Sedivy I, Schleppi P (2010). Estimating leaf area index in different types of mature forest stands in Switzerland: a comparison of methods. European Journal of Forest Research 129 (4): 543-562. - doi: 10.1007/s10342-009-03538

Van Gardingen PR, Jackson GE, Hernandez-Daumas S, Russell G, Sharp L (1999). Leaf area index estimates obtained for clumped canopies using hemispherical photography. Agricultural and Forest Meteorology 94 (3-4): 243-257. - doi: 10.1016/S0168-1923(99)00018-0

Zhang Y, Chen JM, Miller JR (2005). Determining digital hemispherical photograph exposure for leaf area index estimation. Agricultural and Forest Meteorology 133 (1-4): 166-181. - doi: 10.1016/j.agrformet.2005.09.009

Zhao D, Lv M, Wang P, Yang T, An S (2014). Can the plant area index of a submerged vegetation canopy be estimated using digital hemispherical photography? Agricultural and Forest Meteorology 192-193: 69-77. - doi: 10.1016/j.agr formet.2014.03.008 